\title{
Organocatálise: Conceitos e Aplicações nas Reações de Aldol, Adição Conjugada e Henry
}

\author{
Diego S. Alves, Milenna M. Sena, Felipe A. Viana \& Rafael O. Rocha
}

A organocatálise é um dos campos da química orgânica de maior destaque e de grande potencial da atualidade. Nos últimos anos, um crescente número de publicações neste campo tem sido reportado onde pequenas moléculas orgânicas quirais são utilizadas como catalisadores para indução de assimetria, livre de metal, levando à obtenção de intermediários versáteis para a síntese de compostos com potencial farmacológico elevado. Esse interesse se deve à praticidade das metodologias e às altas seletividades obtidas nas diferentes reações já estudadas, tais como, reações de adição aldólica, adição de Michael e reações de Henry. Mais recentemente, esforços têm sido aplicados na síntese de novos organocatalisadores quirais, seja por pequenas modificações estruturais de moléculas já empregadas em organocatálise, tais como os aminoácidos e alcalóides naturais do tipo cinchonas e cinchonidinas, ou até mesmo pela síntese de guanidinas, tiouréias e sulfonamidas quirais, o que tem se mostrado como um ramo em pleno crescimento para aplicação e desenvolvimento de metodologias em sínteses enantiosseletivas.

Palavras-chave: Organocatálise, enantiosseletividade, diastereosseletividade, reação de aldol, reação de adição conjugada e reação de Henry.

Organocatalysis is one of the most outstanding field of organic chemistry and is of great potential today. In recent years, a growing number of papers in this field have been reported where small molecules are used as chiral catalysts for metal-free asymmetric induction, leading to versatile intermediates for the synthesis of compounds with various pharmacological properties. This interest is due to the simplicity of methodologies and the high selectivities obtained in different organic reactions that have been studied, such aldol reactions, Michael reactions and Henry reactions. More recently, efforts have been applied to the synthesis of new chiral organocatalysts, either by small structure modifications in molecules already employed in organocatalysis such amino acids, naturally occurring alkaloids cinchonidine and cinchonine-type, or the synthesis of chiral guanidines, thyourea and sulfonamides, which has been shown as a growing field for application and development of methodologies in enantioselective synthesis

Keywords: Organocatalysis, enantioselectivity, diastereoselectivity, aldol reaction, conjugate addition reaction, Henry reaction. 


\section{Introdução}

A assimetria em sistemas biológicos é de fundamental importância uma vez que muitas, se não a maioria das substâncias biológica e farmacologicamente ativas, apresentam centros estereogênicos em sua estrutura molecular que as tornam ativas para determinados sítios ativos (enzimas) nos organismos vivos através de interações fármaco-receptor. Há moléculas cuja ação biológica só é observada para um determinado enantiômero, sendo o outro enantiômero inativo ou de ação adversa ${ }^{1}$.

Muitas metodologias para síntese enantiosseletiva têm sido investigadas, incluindo catálises heterogênea e homogênea mediada por metais de transição, catálise ácida ou básica e biocatálise ${ }^{2}$. Nos últimos anos, têm-se buscado novos catalisadores que sejam comercialmente disponíveis, de baixo custo e que possam induzir assimetria desejável para diversas reações orgânicas. Com base neste objetivo (tendência), é que surgiu a organocatálise.

A organocatálise é um dos campos da química orgânica de maior destaque da atualidade e de grande potencial, tendo despertado o interesse de inúmeros grupos de pesquisa no mundo todo. Trata-se da aplicação de pequenas moléculas orgânicas quirais cuja função é catalisar de forma eficiente e enantiosseletiva a formação de centros estereogênicos oriundos de novas ligações formadas entre os substratos de partida. Esse interesse se deve à praticidade das metodologias e às altas seletividades obtidas nas diferentes reações já estudadas.

Nos últimos onze anos, um crescente número de publicações neste campo tem sido reportado ${ }^{3}$ onde pequenas moléculas orgânicas quirais são utilizadas como catalisadores para indução de assimetria, livre de metal, levando à obtenção de intermediários versáteis para a síntese de compostos com potencial farmacológico elevado. Em 2008, Amarante e Coelho ${ }^{4}$ divulgaram um levantamento bibliográfico feito pelo sítio do SciFinder, utilizando o termo organocatálise como palavra-chave, do ano de 1971 a meados de 2008, mostrando a evolução no número de publicações relacionadas a essa promissora área. Aqui, é apresentada uma pesquisa complementar na qual foi utilizado o termo organocatálise como palavrachave, no sítio Web of Science (de 1971 a novembro de 2011). Apesar de pequenas divergências numéricas, ambas as pesquisas demonstraram que o número de publicações nessa área vem aumentando expressivamente (Figura 1).

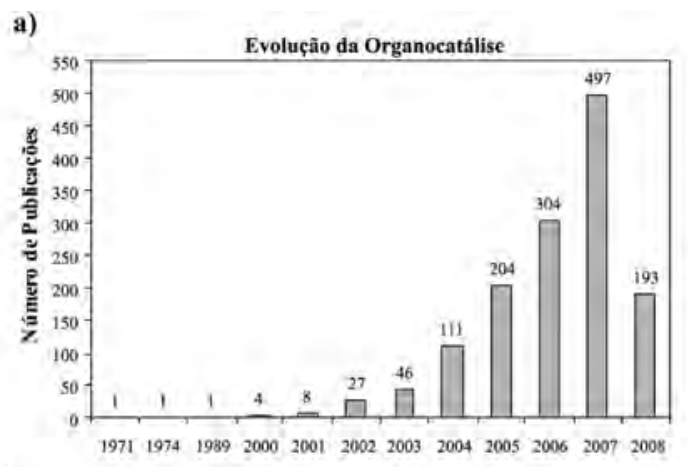

b)

Ano

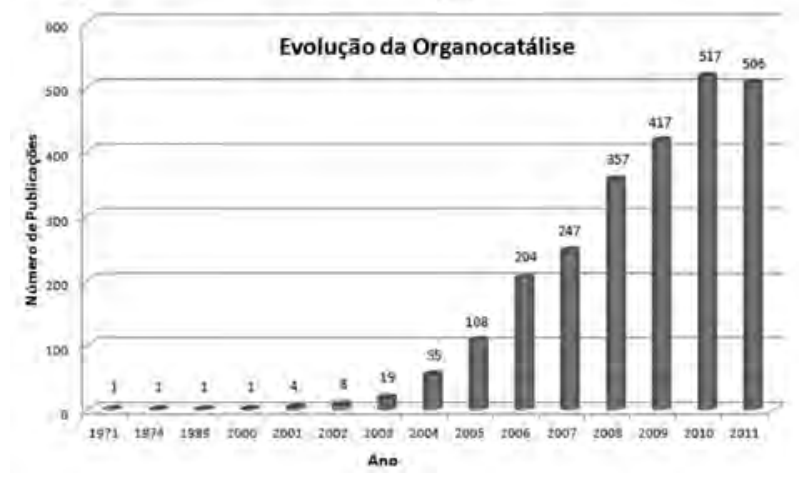

Figura 1. a) Gráfico demonstrativo da evolução da organocatálise de 1971 a 2008, obtido por Amarante e Coelho no sítio do SciFinder ${ }^{4}$. b) Gráfico do atual panorama das publicações na área da organocatálise, obtido no sítio do Web of Science (http://apps.webofknowledge.com/ summary.do?SID=2F\%403MaeFLbfaDbA9klg\&product $=$ WOS\&q id=21\&search_mode=GeneralSearch, pesquisa realizada em 24 de novembro de 2011).

Nos primeiros trabalhos descritos na literatura, foi utilizada uma molécula orgânica pequena, simples e que apresenta todas essas características: a prolina (1), que demonstrou ser bastante promissora (Figura 2). Ela é uma molécula quiral abundante, de baixo valor comercial agregado para o isômero natural $(L)$ e comercialmente disponível em ambas as formas enantioméricas.

A prolina é uma molécula quiral bifuncional, com uma função básica e uma função ácida (Figura 2), e que devido a essas características têm sido extensivamente investigada nos últimos anos como catalisador e indutor assimétrico em diferentes tipos de reações, como nas 
reações de aldol ${ }^{5}$, Mannich ${ }^{6}$, Michael ${ }^{7}$, hidrogenação ${ }^{8}$, Baylis-Hillman $^{9}$, Diels-Alder ${ }^{10}$, e multicomponentes ${ }^{11}$ entre outras ${ }^{12}$.

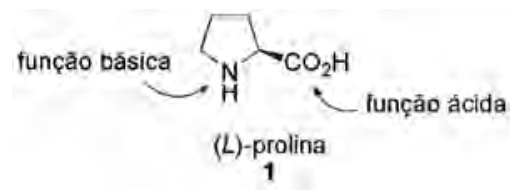

Figura 2. Estrutura molecular da $(L)$-prolina.

A catálise usando prolina, considerada a "enzima mais simples", mimetiza os processos enzimáticos levando à alta reatividade e enantiosseletividade através da ativação dos substratos e organização do estado de transição ${ }^{13}$.

A partir desta metodologia inovadora, na qual se utilizam moléculas orgânicas quirais como catalisadores, MacMillan adotou o termo organocatálise no sentido de diferenciar tal conceito da catálise em que estas moléculas são associadas a compostos metálicos, metodologias estas bastante exploradas até os dias atuais ${ }^{14}$. A organocatálise baseia-se na aplicação de pequenas moléculas orgânicas quirais em processos catalíticos, seja como um catalisador de transferência de fase ou como um ativador direto dos substratos via intermediários do tipo enamina e/ou íon imínio ${ }^{15}$, baseado nas propriedades nucleofílicas e eletrofílicas do catalisador ${ }^{16}$.

Mais recentemente, esforços têm sido aplicados na síntese de organocatalisadores quirais, que têm se mostrado como um ramo em crescente desenvolvimento em síntese enantiosseletiva ${ }^{17}$.

\section{INDUÇÃO ASSIMÉTRICA EM REAÇÕES ALDÓLICAS PROMOVIDAS POR PROLINA}

A reação aldólica é uma das mais importantes reações orgânicas para a formação da ligação C-C entre dois compostos carbonilados ${ }^{18} \mathrm{e}$ é de fundamental importância em biossíntese por proporcionar a construção de unidades de poliacetatos e polipropionatos, presentes em diversos produtos naturais com atividade farmacológica destacada ${ }^{19}$.

Em 1971, Hajos e Parrish ${ }^{20}$ patentearam a primeira aplicação da $(L)$-prolina como catalisador quiral nas reações aldólicas intramoleculares do compostos 2 e 3 para a síntese de intermediários esteroidais e terpenóides (Esquema 1). Neste mesmo ano, Eder-Sauer-Wiechert ${ }^{21}$ patentearam uma nova metodologia para isolar o produto de condensação aldólica direta (6-7), usando quantidade subestequiométrica de prolina em solução de ácido perclórico $\left(\mathrm{HClO}_{4}\right)$.

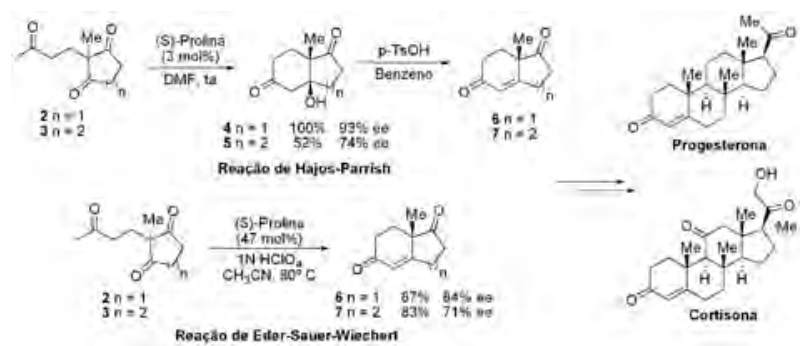

Esquema 1. Primeiras aplicações do uso da $(L)$-prolina como organocatalisador quiral na síntese de intermediários esteroidais ${ }^{20,21}$.

Uma das reações aldólicas mais estudadas para o desenvolvimento de uma metodologia eficiente utilizando a prolina como indutor quiral é a reação entre a acetona e diferentes aldeídos. Vale ressaltar que o ramo da organocatálise ficou adormecido quase 3 décadas, sendo o primeiro trabalho publicado em 1971 e, somente em 2000, é que se retomou o interesse nesta metodologia simples. Para se ter uma idéia, somente em 2000 List e colaboradores ${ }^{22}$ publicaram o primeiro trabalho mostrando o potencial da prolina para catalisar e fornecer os produtos aldólicos em bons rendimentos e excessos enantioméricos. Neste estudo, outros derivados de aminoácidos foram testados como catalisadores, porém não foram tão eficientes quanto a prolina, sendo esta capaz de fornecer os produtos aldólicos de baixo a ótimos rendimentos $(<10-97 \%)$ e bons excessos enantioméricos (40-96\%). O melhor resultado foi obtido quando aplicado o isobutiraldeído obtendo a $\beta$-hidróxi cetona 18 em 97\% de rendimento e 96\% de excesso enantiomérico (Esquema 2).

Variações na metodologia proposta por List vêm sendo descritas na literatura a fim de minimizar alguns inconvenientes, tais como longos tempos reacionais e o uso de um grande excesso da cetona, que dependendo desta, pode-se tornar inviável para uma síntese, sendo preferíveis as metodologias tradicionais. Apesar de esse tipo de estudo ser relativamente recente para processos intermoleculares, diversas modificações já foram realizadas $^{23}$, tais como o uso de diferentes cetonas ${ }^{24}$, modificação estrutural da prolina ${ }^{10 b, 25}$, uso de diferentes tipos de aldeídos ${ }^{26}$ e variação de solventes ${ }^{27}$. 


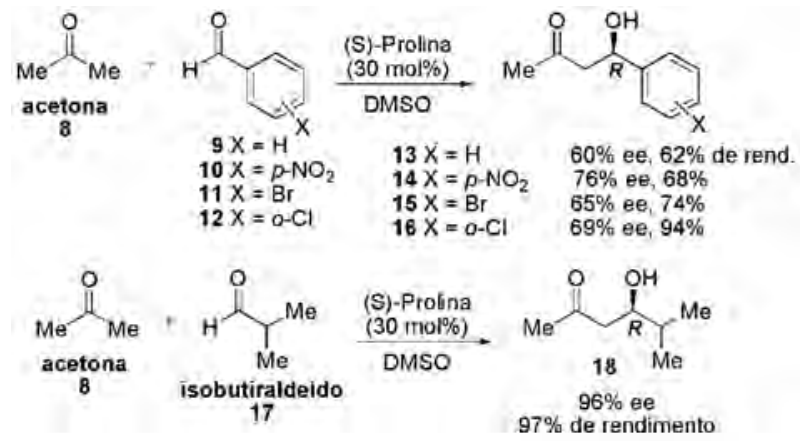

Esquema 2. Aplicação de quantidades catalíticas de $(L)$-prolina na reação de adição aldólica entre acetona e diferentes aldeídos ${ }^{22}$.

Diversos estudos mecanísticos demonstram que as reações de aldol catalisadas por $(L)$-prolina passam inicialmente pela ativação do grupo carbonila do aldeído ou da cetona através da formação in situ do intermediário enamina 19, seguida da adição ao grupo carbonila do aldeído, gerando então o produto de aldol 20. A enantiosseletividade se deve ao estado de transição cíclico formado pela ativação do grupo carbonila do aldeído através da ligação de hidrogênio da função ácida do catalisador ${ }^{28}$ (Esquema 3).

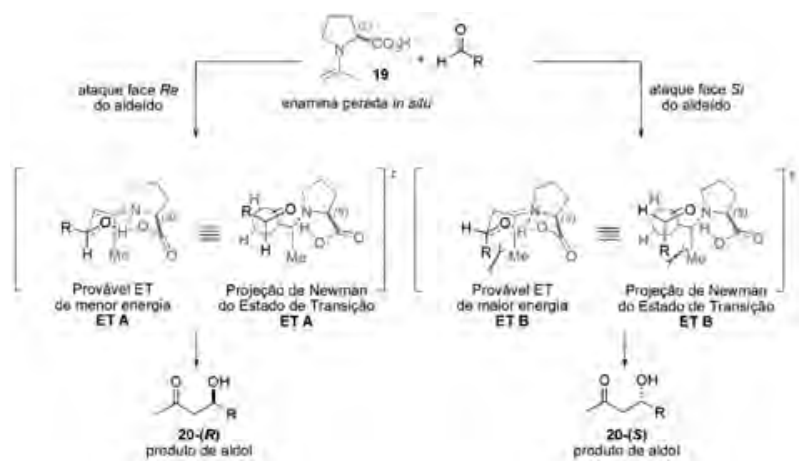

Esquema 3. Mecanismo que explica a enantiosseletividade das reações de aldol mediadas por $(L)$-prolina ${ }^{28}$.

Uma vez que o mecanismo proposto passa por um intermediário enamina, acreditava-se que somente a prolina, por ser um aminoácido com a função amina secundária, poderia ser usado como organocatalisador, e que os demais aminoácidos seriam incapazes de atuar como catalisadores. Entretanto, com o avanço da organocatálise em reações orgânicas nos últimos anos ${ }^{29}$, diferentes aminoácidos, pequenos peptídeos e aminas primárias quirais têm sido descrito como potentes indutores quirais ${ }^{30}$.

\section{APLICAÇÕES DE ORGANOCATALISADORES EM REAÇÕES DE ADIÇÃO CONJUGADA ENANTIOSSELETIVAS}

A organocatálise vem sendo explorada nas reações de adição conjugada, também conhecidas como adição de Michael ou adição 1,411. Esse tipo de reação tem um papel importante em síntese orgânica uma vez que, além de promover a formação da ligação carbono-carbono, também pode gerar um ou mais centros estereogênicos no produto final. Assim, além do uso de diversos metais de transição, organocatalisadores derivados de alcalóides 21-24 ${ }^{32}$, sulfonamidas 25, aminoácidos 26, tiouréias 27, entre outros, vêm sendo desenvolvidos e aplicados nas reações de Michael (Figura 3).
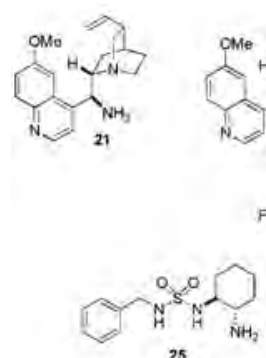

25
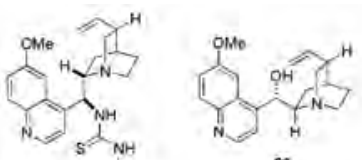

23
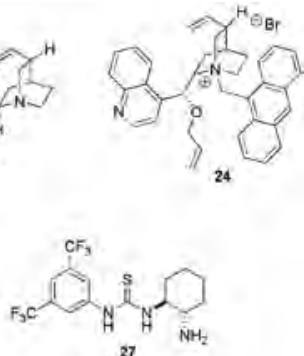

Figura 3. Exemplos de alguns organocatalisadores aplicados em reações de adição conjugada.

$\mathrm{Na}$ Figura 3, estão representados diferentes organocatalisadores derivados de alcalóides naturais do tipo cinchonidina e cinchonina 21-24, aminoácidos naturais 26 e diaminas quirais 25 e 27 , sendo que a maioria das modificações estruturais estudadas baseiase na variação de parte da estrutura de moléculas comercialmente disponíveis. Dentre as maiores modificações podem ser destacadas: a inversão de centros estereogênicos, substituição de grupamentos com pouca mobilidade por outros com maior grau de rotação, e ainda, variação de grupos substituintes na perspectiva de mudança de polaridade do substrato (propriedades hidrofóbicas e hidrofílicas), a fim de variar a solubilidade em diferentes solventes, especialmente em soluções aquosas. Todas essas alterações podem influenciar na seletividade da reação dependendo da propriedade que 
mais interfira na formação do estado de transição.

Zhang e Corey ${ }^{33}$ reportaram a aplicação da reação assimétrica de Michael em uma das etapas da síntese do aminoácido (S)-ornitina 31. A reação entre o derivado da glicina 28 e acrilonitrila 29, na presença de $10 \mathrm{~mol} \%$ da cinchonidina 24, forneceu o composto 30 em 85\% de rendimento e pureza enantiomérica de 91\% (Esquema 4).

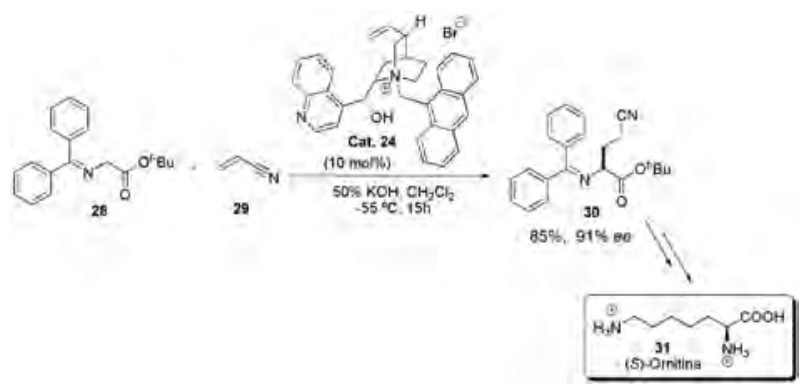

Esquema 4. Adição de Michael enantiosseletiva mediada pelo organocatalisador $\mathbf{2 4}$ como etapa chave na síntese da (S)-Ornitina $\mathbf{3 1}{ }^{33}$.

Com pequenas alterações na estrutura do catalisador 24, Corey e Zhang ${ }^{33}$ realizaram a síntese do aduto 35 a partir da chalcona 32 e acetofenona 33, em $72 \%$ de rendimento e excesso enantiomérico de 80\% (Esquema 5).

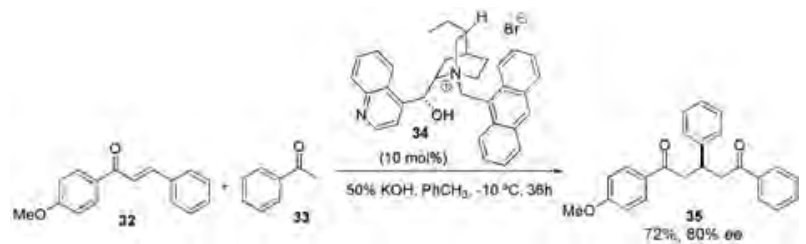

Esquema 5. Primeiro passo da anulação de Robinson apresentada por Corey e Zhang ${ }^{33}$.

Hébrault et al. ${ }^{34}$, aplicando catalisadores derivados dos alcalóides quinidina e quinina, mostraram que a inversão dos centros estereogênicos dos catalisadores pode inverter também a estereoquímica dos adutos de Michael. A reação estudada foi adição de dimetilmalonato 37 à pentilcicloexanona 36 , na presença dos catalisadores 38 e 39. Foi observado que a pureza enantiomérica dos adutos de Michael $\mathbf{4 0}$ e $\mathbf{4 1}$ obtidos variarou nas mesmas condições reacionais. Quando o derivado da quinina $\mathbf{3 8}$ está presente, o produto principal foi o aduto de Michael $\mathbf{4 0}$, com rendimento de $90 \%$, excesso enantiomérico de $91 \%$ e configuração $(2 S, 3 R)$. Já com o derivado da quinidina 39, o aduto $\mathbf{4 1}$ foi o preferencial e o mesmo foi isolado em menor rendimento (80\%), pureza enantiomérica de 60\% e configuração $(2 R, 3 S)$ (Esquema 6).

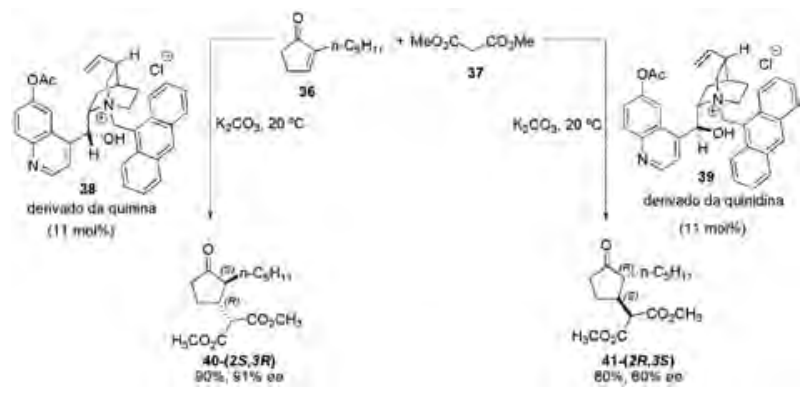

Esquema 6. Adição do dimetilmalonato 37 à cetona $\alpha, \beta$-insaturada $\alpha$ substituída 36, na presença de catalisadores assimétricos derivados da quinina 38 e quinidina $39^{34}$.

De acordo com Hébrault e colaboradores ${ }^{34}$, os substituintes aromáticos e volumosos bloqueiam duas das três faces acessíveis aos íons de amônio, o que limita o setor de posicionamento do ânion do malonato, e a adição na cetona $\alpha, \beta$-insaturada pode ter a influência de três efeitos: i) ligação de hidrogênio entre o grupo hidroxila do organocatalisador e o oxigênio da cetona; ii) interações do tipo dispersão de London entre o carbono $\beta$ eletrodeficiente da cetona insaturada e o grupamento metoxila do catalisador; iii) interações estéreas dos grupos aromáticos volumosos com o grupo alquila do carbono $\alpha$ da cetona (Figura 4).

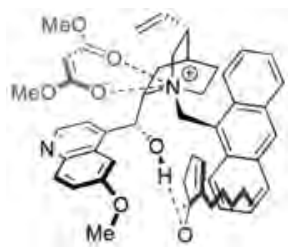

Figura 4. Modelo de aproximação entre o doador e o aceptor de Michael proposto por Hébrault e colaboradores ${ }^{34}$.

Jorgensen e colaboradores ${ }^{35}$ também investigaram a adição enantiosseletiva de malonatos a cetonas $\alpha, \beta$ insaturadas. No entanto, tais reações foram estudadas utlizando a imidazolidina quiral $\mathbf{4 3}$ em quantidades catalíticas. Diferentes malonatos simétricos e assimétricos foram testados nessa metodologia, uma vez que estudos similares de adição conjugada desenvolvidos por Yamaguchi et $a l .^{36}$ já haviam demonstrado que o grupo éster pode afetar a indução assimétrica desse tipo de reação. Assim, 
sob agitação e à temperatura ambiente, misturaram-se os malonatos 37a-i à enona $\alpha, \beta$-insaturada 42 , na presença de $10 \mathrm{~mol} \%$ da imidazolidina 43. Os rendimentos dos adutos de Michael 44 obtidos variaram de 5-93\% e os excessos enantioméricos entre 71-99\% (Esquema 7).

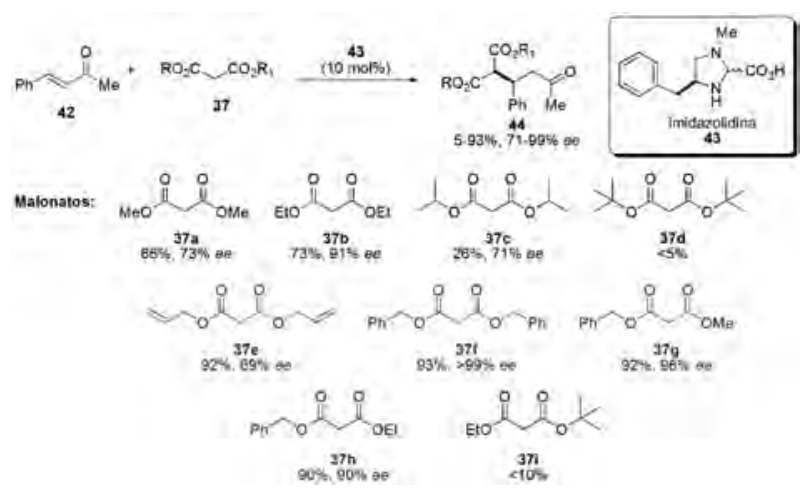

Esquema 7. Adição enantiosseletiva de malonatos à enona acíclica 42, catalisada pela imidazolidina $\mathbf{4 3 ^ { 3 5 }}$.

Analisando os resultados obtidos, Jorgensen e colaboradores destacaram que para os malonatos 37c, 37d e 37i os rendimentos foram extremamente baixos comparados aos demais, e justificaram pela presença de substituintes $\mathrm{R}$ estericamente mais impedidos, destacando ainda que os malonatos com grupos $\mathrm{R}$ menos volumosos apresentaram tanto rendimentos como pureza enantiomérica bastante destacados, como por exemplo, os malonatos 37e-h. Com isso, os autores mantiveram fixo o malonato que apresentou a melhor enantiosseletividade (dibenzilmalonato 37f), variando com diferentes enonas 45 na presença de $10 \mathrm{~mol} \%$ do organocatalisador 43 . Os adutos de Michael $\mathbf{4 6}$ foram isolados em rendimentos que variaram de 2-99\% e excessos enantioméricos de $58-99 \%$. Em todos os casos, os produtos isolados apresentaram a configuração $R$ do centro estereogênico formado (Esquema 8).
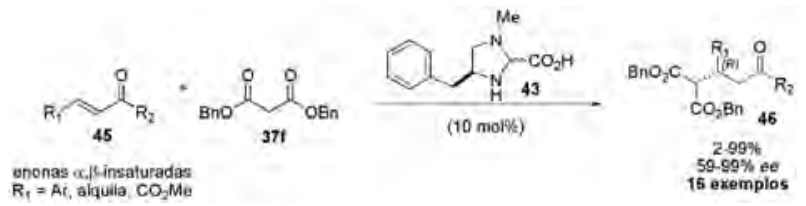

Esquema 8. Adição enantiosseletiva do dibenzilmalonato $\mathbf{3 7 f}$ a diferentes enonas acíclicas $\mathbf{4 5}^{35}$.

Os autores destacaram que a introdução de grupos retiradores ou doadores de elétrons, quando $R_{1}$ é um grupo aromático, não comprometeu nem o rendimento nem a enantioseletividade dos produtos obtidos, com exceção da enona contendo o grupo 4- $N, N$-dimetila, que apresentou rendimento de $58 \%$ e pureza enantiomérica de $77 \%$. Substituintes alquilas em $\mathrm{R}_{2}$ da enona acabaram exigindo tempos reacionais maiores e os rendimentos foram mais baixos, principalmente naquelas mais impedidas que podem influenciar a taxa de formação do intermediário pela aproximação do catalisador à enona, já que nesse tipo de reação ocorre a ativação do aceptor de Michael pela formação do íon imínio (Figura 5).

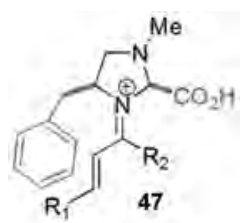

Figura 5. Ativação do aceptor de Michael pela formação do íon imínio $47^{35}$.

Pela estrutura do intermediário imínio $\mathbf{4 7}$ formado in situ, percebe-se que o posicionamento dos grupos benzila e carboxila (representado em vermelho) justifica o ataque do malonato na face Re do intermediário 47.

Em 2001, List e colaboradores ${ }^{37}$ publicaram os resultados das reações de adição conjugada de quatro diferentes cetonas $\mathbf{4 8}$ com quatro diferentes nitro olefinas 49, na presença da $(L)$-prolina 1 como catalisador (Esquema 9). Em todos os casos, os adutos de Michael 50a-g foram obtidos em boa diastereoseletividade syn/ anti, mas com baixos valores de enantiosseletividade, o que se contrapõe aos resultados apresentados para as reações de Mannich ${ }^{38}$ e aldol ${ }^{39}$ catalisadas pela $(L)$ prolina, nas quais ambas também passam pela formação do intermediário enamina.

Enders e $\mathrm{Seki}^{40}$ desenvolveram estudos similares substituindo o solvente DMSO (usado por List e colaboradores $^{37}$ ) pelo metanol. Com isso, foi observado um aumento na enantioseletividade de $7 \%$ para $12 \%$ na formação do aduto de Michael 50a e enantiosseletividades acima de $76 \%$ para compostos similares.

Recentemente, Wang et al. ${ }^{41}$ utilizaram aminotiofosforamidas 52 como catalisadores, ao invés da $(L)$ prolina, na reação de adição de acetona $\mathbf{8}$ a nitro olefinas 
51, obtendo rendimentos que variaram de $67-99 \%$ e excessos enantioméricos acima de 97\% (Esquema 10).

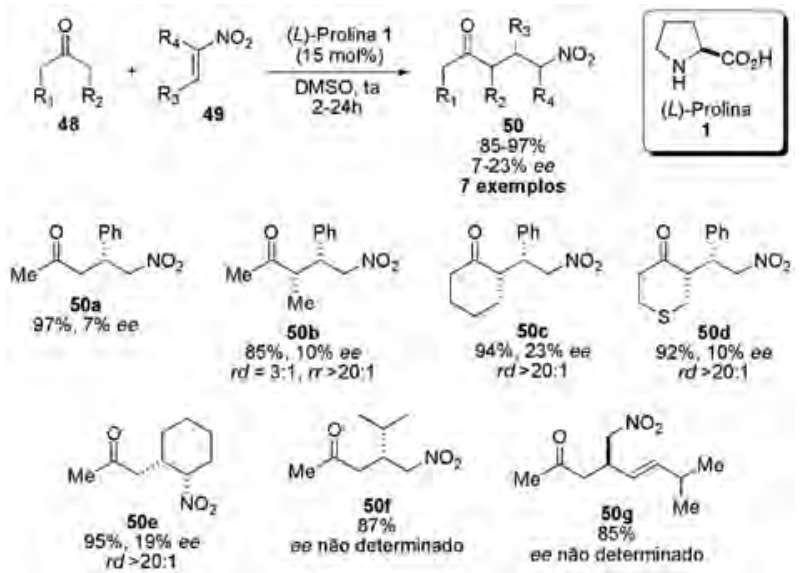

Esquema 9. Adições de Michael de cetonas a nitro olefinas, catalisadas por $(L)$-prolina $\mathbf{1}^{37}$.

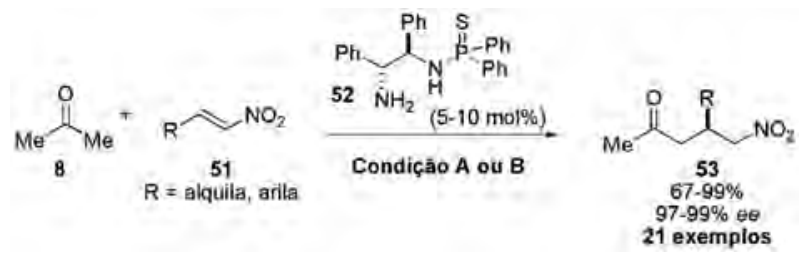

Esquema 10. Adição de Michael de acetona a nitro olefinas catalisada pela amino-tiofosforamida $\mathbf{5 2}^{41}$.

As reações foram realizadas sob duas condições com uma variedade de nitro olefinas. $\mathrm{Na}$ condição A, foram aplicados $10 \mathrm{~mol} \%$ do catalisador 52. Já na condição B, a porcentagem do catalisador 52 foi de 5 mol\%, combinado com o $p$-nitrofenol. Em ambas as condições, foi utilizado tolueno como solvente, a uma temperatura de $20{ }^{\circ} \mathrm{C}$. Os resultados evidenciaram que em ambas condições os produtos foram isolados em excelentes rendimentos (75-99\% condição A e 67-99\% condição B) e excessos enantioméricos (97$99 \%$ ), tanto para as nitro olefinas aromáticas, contendo substituintes $\mathrm{R}$ com retiradores de elétrons, quanto nas que possuíam grupos doadores. Com isso, demonstrouse $\mathrm{o}$ alto potencial das amino-tiofosforamidas como catalisadores enantiosseletivos na reação de Michael, com a vantagem de se poder reutilizar o catalisador em pelo menos cinco outras reações sem que se perca a eficiência na enantiosseletividade do mesmo.
Os autores ainda apresentaram uma proposta de estado de transição da reação da acetona 8 com o $(E)$ - $\alpha$-metil- $\beta$ nitroestireno 54, na presença de $20 \mathrm{~mol} \%$ do catalisador 52. De modo geral, temos que em uma primeira etapa o grupamento amina do catalisador $\mathbf{5 2}$ reage com o grupo carbonila da acetona para gerar a enamina in situ. Em seguida, o hidrogênio ligado ao átomo de nitrogênio da tiofosforamida orienta o grupo $-\mathrm{NO}_{2}$ por interação de hidrogênio, e assim favorece o ataque da enamina na face Re do nitro estireno (Esquema 11).

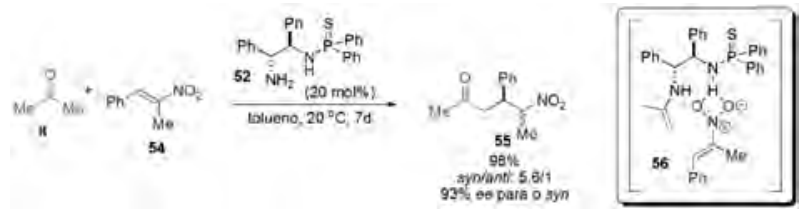

Esquema 11. Possível estado de transição entre o intermediário enamina formado in situ e o $(E)-\alpha$-metil- $\beta$-nitroestireno $54^{41}$.

Alguns catalisadores baseados na estrutura da tiouréia também ganharam muito espaço em reações do tipo Michael. Tsogoeva et al. ${ }^{42}$ testaram a influência desse tipo de catalisador na reação entre o (E)- $\beta$-nitroestireno 57 e a acetona 8 . O produto 50a foi obtido em rendimentos e seletividades que variaram de $50-98 \%$ e excesso enantiomérico de 3-91\%, quando utilizados os catalisadores $\mathbf{5 8 - 6 2}$ sob as mesmas condições reacionais (Esquema 12).

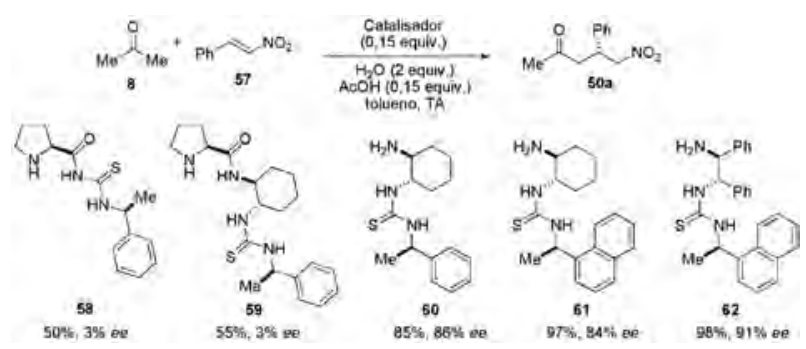

Esquema 12. Reação de adição conjugada da acetona a nitro estirenos, na presença de catalisadores do tipo tiouréi ${ }^{42}$.

Os autores destacaram que os catalisadores 58 e 59, que apresentam o grupamento quiral básico similar ao da $(L)$-prolina, apresentaram enantioseletividades muito baixas. Diferentemente destes, foi observado um aumento significativo nas enantiosseletividades quando a porção da $(L)$-prolina foi substituída por uma diamina 
quiral, demonstrando a grande importância dessa parte da molécula. Os autores propuseram duas possíveis interações entre a enamina formada com o catalisador $\mathbf{6 0}$ e o (E)- $\beta$-nitroestireno 57. Para explicar a estereoquímica do produto principal, foram desenvolvidos cálculos computacionais para os estados de transição de ambos os enantiômeros. Observa-se na figura 6 que as distâncias entre os carbonos a e b é menor durante a formação do enantiômero $R$, bem como existe maior estabilização pela melhor aproximação entre o hidrogênio c com o enxofre do grupamento tiouréia. Destaca-se ainda que a aproximação entre o oxigênio do grupo nitro e o anel aromático conduz a uma maior repulsão e desfavorece a formação do enantiômero $S$.

(a)
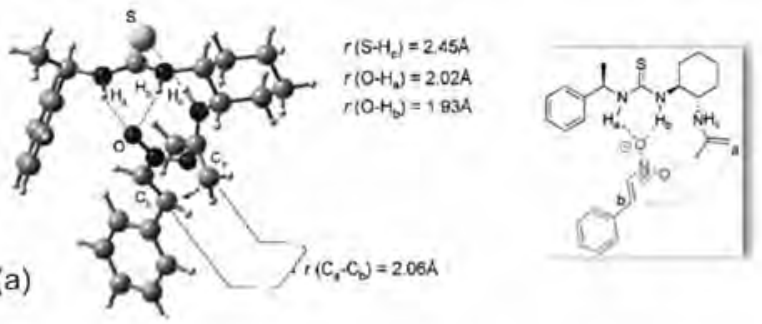

(b)

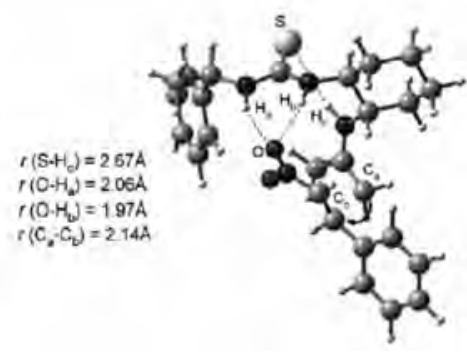

Figura 6. (a) Estado de transição que justifica a formação do enantiômero $R$. (b) Estado de transição que leva à formação do enantiômero $S^{42}$.

Substratos damalonitrilatambémjáforamempregados em reações assimétricas de adição conjugada com o uso de organocatalisadores ${ }^{43}$. Yan et. $a l .{ }^{44}$ destacaram que a adição a dienonas conformacionalmente flexíveis 63, na presença de catalisadores derivados de alcalóides do tipo cinchonina, podem conduzir a produtos completamente diferentes daquelas metodologias descritas com dienonas conformacionalmente mais restritas $\mathbf{6 7}^{45}$ (Esquema 13). No primeiro caso, ocorrem duas adições de Michael enantiosseletivas, sendo que a segunda adição é intramolecular, levando à formação de cicloexanonas substituídas 66. No segundo caso, inicialmente ocorre uma adição de Michael enantiosseletiva seguida de uma ciclização intramolecular, levando à formação de amino-piranonas substituídas 69. Diferentes dienonas conformacionalmente flexíveis foram testadas e os produtos foram obtidos em rendimentos que variaram de $35-87 \%$ e excessos enantioméricos de 95-99\%. Já as diferentes dienonas conformacionalmente restritas utilizadas forneceram os respectivos produtos em rendimentos quantitativos e valores de ee de $99 \%$.

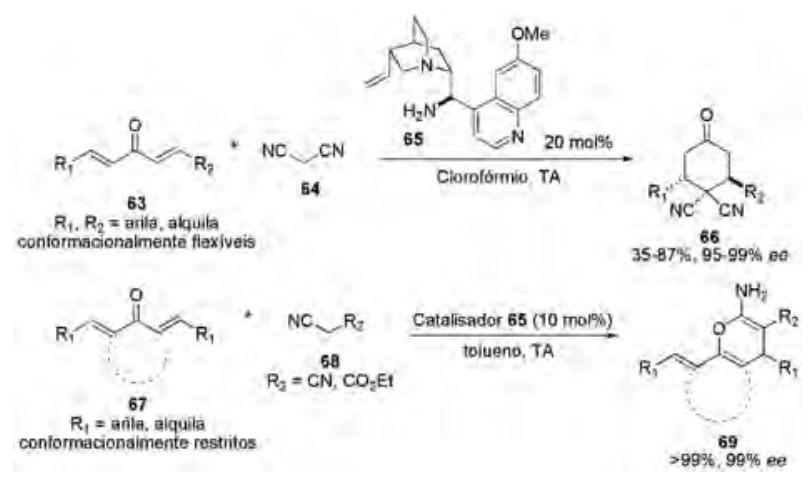

Esquema 13. Adição conjugada de malonitrilas a dienonas com e sem restrições conformacionais ${ }^{45}$.

Connon e McCooey ${ }^{46}$ também desenvolveram estudos em reações de Michael organocatalisadas, mas aplicaram derivados da cinchona para formar o intermediário enamina (Esquema 14). A metodologia apresentada mostrou-se bastante tolerante a vários substratos nitro olefínicos contendo grupos alquila e arila. No caso das reações envolvendo aldeídos, a configuração predominante observada foi a $(R, R)$ com rendimentos que variaram de 76-97\% e excessos enantioméricos entre $66-95 \%$. No caso do uso de cetonas, a configuração dos produtos obtidos foi a $(S, S)$ e rendimentos que variaram de $71-91 \%$ e excessos enantioméricos entre 69-99\%. Em todos os casos, a seletividade syn foi favorecida.

Para justificar a inversão da configuração frente aos substratos, os autores propuseram os estados de transição 76 e 77 onde o intermediário enamina $(E)$ derivado da cetona se aproxima preferencialmente pela face $R e$ do nitro composto e, no caso da enamina derivada do aldeído, a aproximação ocorre pela face Si. Este arranjo minimiza interações estéreas entre os resíduos alquílicos e os substituintes do catalisador. Atribuiu-se também 
grande importância à presença do co-catalisador ácido, pois a ligação de hidrogênio formada entre o nitrogênio do sal quaternário de amônio e o oxigênio do grupo nitro dificulta a polimerização dos substratos nitro olefínicos, o que vinha sendo observado quando na sua ausência.

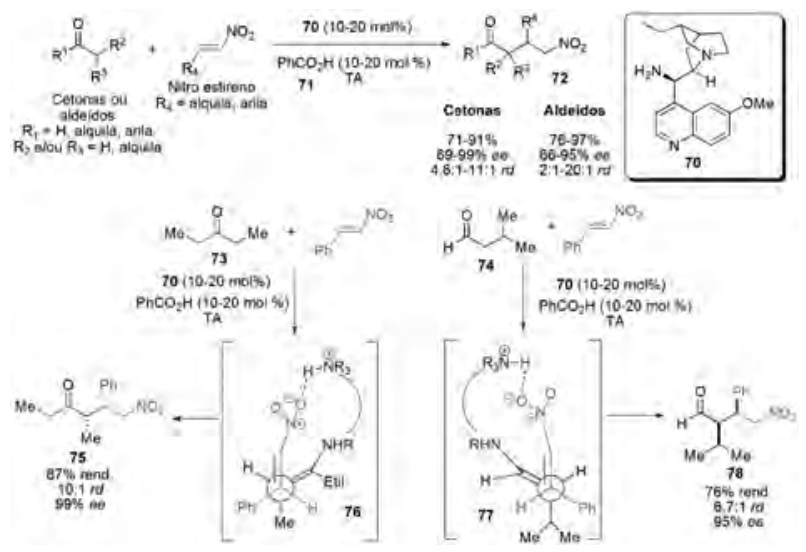

Esquema 14. Preparação de aldeídos e cetonas quirais ${ }^{46}$.

Singh et. al. ${ }^{47}$ reportaram estudos de adições conjugadas de ilídeos de fósforo a nitro olefinas, na presença de um catalisador orgânico quiral, seguidas da reação de Wittig. Nesse trabalho, os autores não determinaram a estereoquímica absoluta dos adutos de Michael formados nem desenvolveram estudos mecanísticos a respeito do processo catalítico de indução assimétrica (Esquema 15).

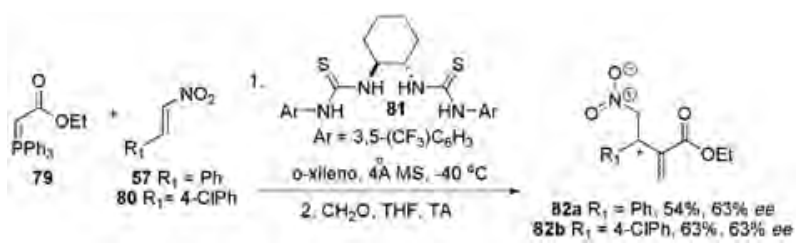

Esquema 15. Preparação de $\gamma$-nitro compostos via adição de ilídeos de fósforo seguida da reação de Wittig ${ }^{47}$.

Os resultados mostraram rendimentos e pureza enantiomérica que variaram de ruins a moderados. O melhor excesso enantiomérico $(63 \%$ ee) foi obtido quando utilizado o nitroestireno 57 e o catalisador 81, juntamente com peneira molecular, tendo $o$-xileno como solvente. O produto 82a foi isolado em $54 \%$ rendimento após $6 \mathrm{~h}$ de reação. Usando as mesmas condições reacionais, mas alterando-se a nitro olefina 57 para a
80, a pureza enantiomérica manteve-se a mesma, mas o rendimento passou para $63 \%$.

Recentemente, Cheng e colaboradores $^{48}$ realizaram estudos aplicando catalisadores derivados da cinchona, tiouréia e aminas primárias simples em reações de adição de ilídeos de fósforo 83 a cetonas $\alpha, \beta$-insaturadas $\mathbf{8 4}$ co-catalisadas com alguns ácidos orgânicos. Os produtos $\mathbf{8 6}$ foram isolados em rendimentos que variaram de $46-67 \%$, com excessos enantioméricos entre 72-95\% quando utilizados o catalisador 65 e o co-catalisador 85 (Esquema 16).

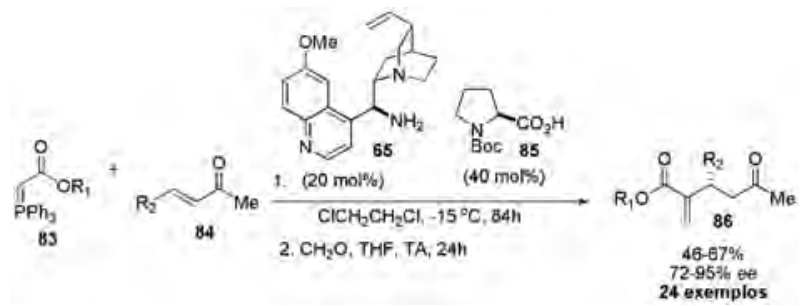

Esquema 16. Síntese assimétrica de $\alpha$-metileno- $\delta$-cetoésteres via reação one-pot de adição de Michael/Reação de Wittig ${ }^{48}$.

Os autores fizeram uma proposta do estado de transição 88 que justifica a configuração $S$ dos adutos de Michael formados. Inicialmente, é formado um intermediário imina entre o grupo $\mathrm{NH}_{2}$ do catalisador 65 e a cetona $\alpha, \beta$-insaturada 87. Na presença de 2 equivalentes do co-catalisador $\mathbf{8 5}$, ocorre a protonação da imina e do grupo quinuclidínio o qual coordena com o ilídeo de fósforo, levando à formação do composto $\mathbf{8 9}$. Na etapa seguinte, acontece a reação de Wittig quando da presença de paraformaldeído, fornecendo os $\alpha$-metileno$\delta$-cetoésteres quirais (Esquema 17).

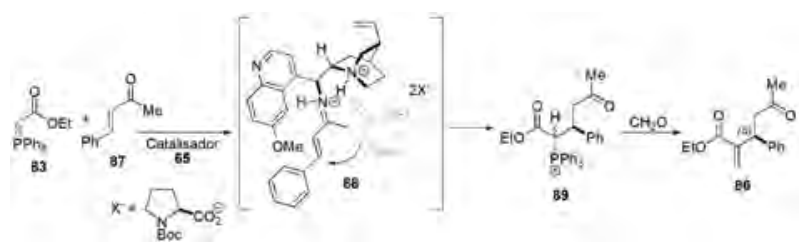

Esquema 17. Proposta de estado de transição para a etapa da adição de Michael de ilídeos de fósforo a cetonas $\alpha, \beta$-insaturadas ${ }^{48}$.

Hayashi et. al. ${ }^{49}$ desenvolveram uma síntese enantiosseletiva para o Baclofen 93 utilizando o organocatalisador $\mathbf{2 6}$ derivado da prolina na etapa chave. O Bacoflen é o componente prescrito para o 
tratamento de espasmos, particularmente nos pacientes com esclerose muscular. Este também pode ser administrado no tratamento de dependentes de cocaína, inibindo a liberação do neurotransmissor dopamina no cérebro, cortando o "êxtase" causado pela droga. Nesta síntese, foram utilizados o 4-clorocinamaldeído 90 e o nitrometano 91, na presença do catalisador difenilprolinol silil éter 26, fornecendo o aduto de Michael $92 \mathrm{com}$ pureza enantiomérica de 91-95\% (Esquema 18).

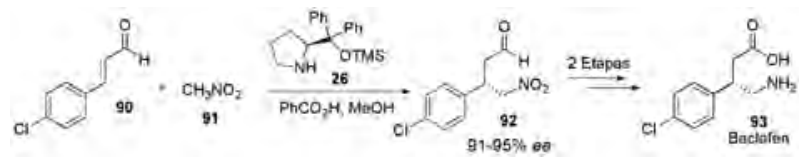

Esquema 18. Síntese enantiosseletiva do Baclofen organocatalisada pelo difenilprolinol silil éter $\mathbf{2 6}^{49}$.

Outra aplicação interessante de organocatalisadores emreações deadiçãoconjugada foirecentementereportada por Hanessian e colaboradores ${ }^{50}$. Eles propuseram uma nova estratégia de síntese enantiosseletiva para a molécula $(S)-(+)-\mathbf{9 8}$, que vem sendo preparada de forma racêmica e tem demonstrado excelente resposta contra as atividades neuronais causadas pelo óxido nítrico.

A etapa chave da síntese passa por uma adição de Michael enantiosseletiva do 5-bromo-indol 94 ao $\gamma$-amino-aldeído $\alpha, \beta$-insaturado 95a-b, catalisada pelo catalisador de MacMillan 96 (Esquema 19). Vários grupos protetores do grupo amina foram testados e os produtos foram isolados em rendimentos que variaram de $65-100 \%$ e os excessos enantioméricos variaram de $90,5: 9,5 \%$ a $96: 4 \%$.

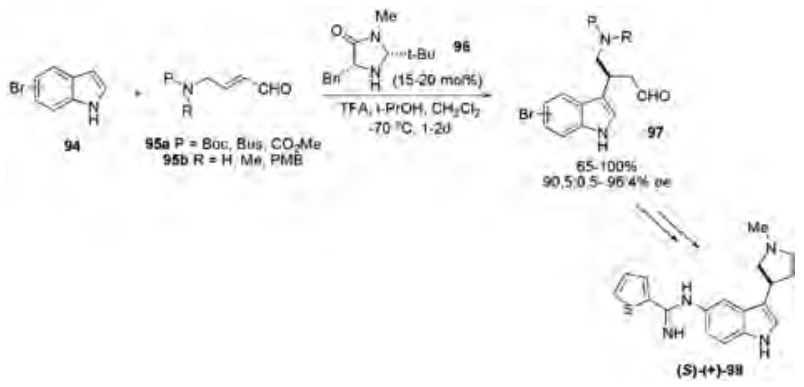

Esquema 19. Nova estratégia de síntese enantiosseletiva para a molécula (S)-(+)-98, fazendo uso do catalisador de MacMillan $\mathbf{9 6}^{50}$.

Yang e Carter ${ }^{51}$ também reportaram a aplicação de catalisadores orgânicos para melhorar a seletividade da adição de Michael intramolecular em uma das etapas da síntese da licopodina 102, uma substância que tem mostrado propriedades medicinais interessantes como atividade antitérmica e anticolinesterase. A etapa chave é a adição de Michael enantiosseletiva intramolecular do composto 99, mediada pelo organocatalisador do tipo sulfonamida 100. O produto $\mathbf{1 0 1}$ foi obtido em $71 \%$ de rendimento e $88 \%$ de excesso enantiomérico (Esquema 20).
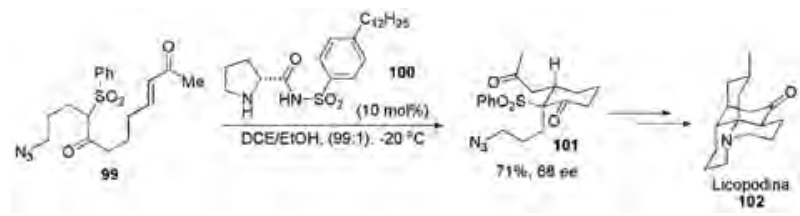

Esquema 20. Etapa chave da síntese enantiosseletiva da Licopodina $\mathbf{1 0 2}^{51}$.

\section{A Organocatálise nas Reações de Henry Enantiosseletivas}

As reações de Henry enantiosseletivas mediadas por organocatalisadores têm sido bastante exploradas nos últimos anos. Estas reações consistem na adição de um nitro alcano a aldeído ou cetona, na presença de uma base. Como produto, obtém-se um $\beta$-nitro álcool através da formação de uma nova ligação $C-C^{52}$. O interesse em tais reações consiste principalmente no fato de seus produtos serem intermediários importantes para a síntese de alguns fármacos, inseticidas, bactericidas e outros compostos de interesse biológico ou industrial. Na literatura, encontram-se alguns artigos de revisão e diversos trabalhos publicados sobre catálise assimétrica aplicada às reações de nitroaldol, onde se observa que diversos catalisadores de complexos metálicos e organocatalisadores têm sido utilizados a fim de induzir enantio e diasteroseletividade ${ }^{53,54,55}$.

Em 2007, o grupo liderado por $\mathrm{Shi}^{56}$ preparou o organocatalisador quiral 104 e aplicou em reações de Henry entre aldeídos aromáticos e nitrometano, a fim de observar a enantiosseletividade (Esquema 21). Após vários experimentos para otimização da reação, concluiuse que $i \mathrm{Pr}_{2} \mathrm{NEt}$ apresentou-se como a melhor base. Os produtos formados apresentavam configuração $(S)$ e 0 excesso enantiomérico variou de 22 a $75 \%$.

Para explicar a estereoquímica e a forma como age o 
organocatalisador 104, os autores propuseram o modo de interação entre o catalisador e os precursores da reação ${ }^{56}$. O aldeído 103 interage com o organocatalisador 104, formando ligações de hidrogênio com os hidrogênios do grupo tiouréia, enquanto o hidrogênio da base ativa o nitrometano, formando o rearranjo estrutural 105 do estado de transição (Figura 7).

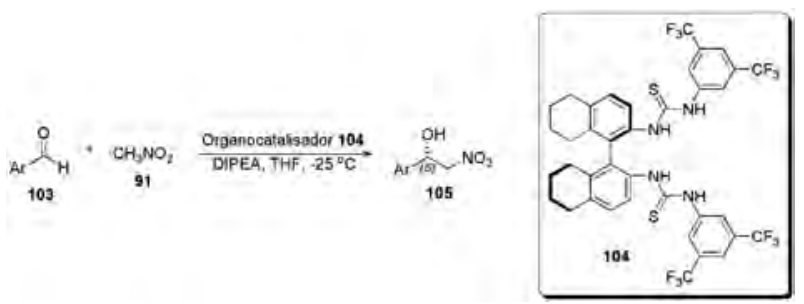

Esquema 21. Estudo enantiosseletivo da reação de Henry, utilizando o organocatalisador $\mathbf{1 0 4}^{56}$.

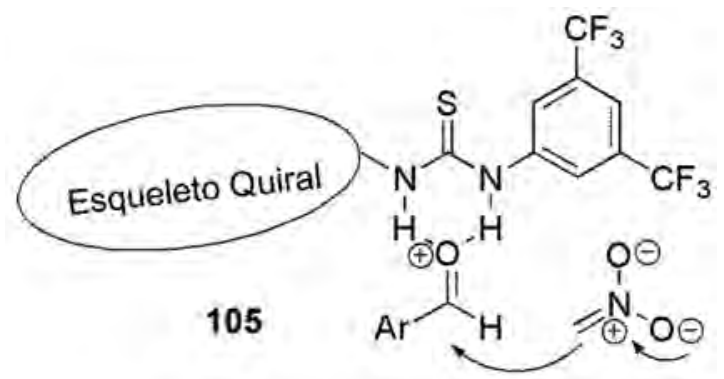

Figura 7. Interação entre o organocatalisador 104 e os substratos, na reação de Henry organocatalisada ${ }^{56}$.

Terada e colaboradores $^{57}$ estudaram a enantiosseletividade e diastereosseletividade de reações de nitroaldol, utilizando como organocatalisadores guanidinas quirais 106 (Figura 8). Estas guanidinas apresentam caráter básico e podem formar ligações de hidrogênio com os precursores, facilitando a reação e induzindo a formação do produto quiral.

Neste estudo, foram avaliados os resultados do efeito dos grupos substituintes aromáticos no ligante. O catalisador $\mathbf{1 0 6 h}$ apresentou os melhores resultados tanto com relação ao rendimento quanto à enantiosseletividade na reação entre nitrometano 91 e benzaldeído $103(\mathrm{Ar}=$ $\mathrm{C}_{6} \mathrm{H}_{5}$ ). Terada e colaboradores investigaram as limitações e eficiência do organocatalisador $\mathbf{1 0 6 h}$, frente a diferentes solventes, nas reações do nitrometano e vários aldeídos. Os excessos enantioméricos dos produtos 105 variaram de $47-68 \%$ e os rendimentos ficaram entre 40 e $97 \%$.
Para avaliar a diastereosseletividade, foi utilizado o nitroetano e diferentes aldeídos aromáticos, na presença de $10 \mathrm{~mol} \%$ do catalisador 106h. Os adutos de Henry 108 foram isolados em rendimentos entre $49-99 \%$ e valores de ee entre $53-81 \%$ para o isômero anti e 10-89\% para o isômero syn (Esquema 22).
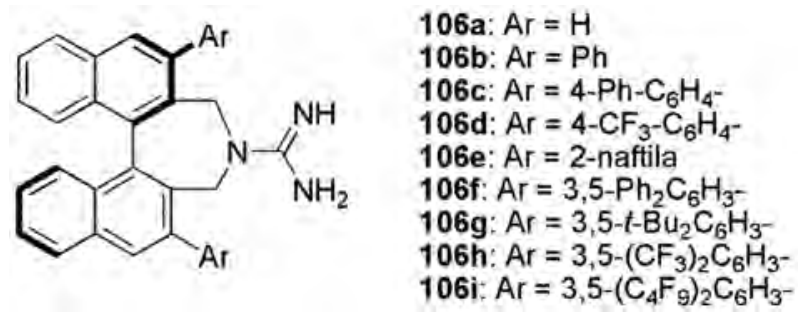

Figura 8. Organocatalisadores do tipo guanidina ${ }^{57}$.

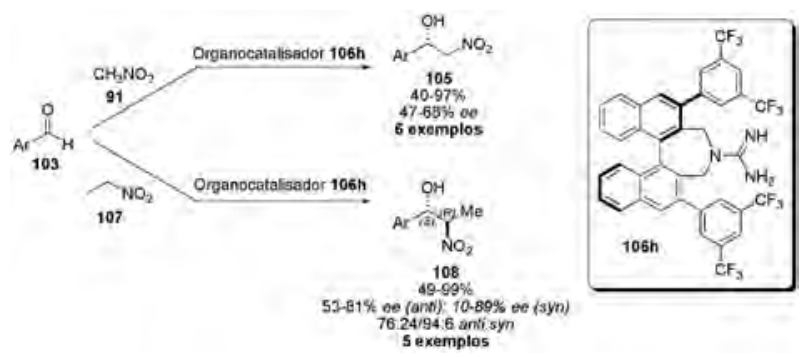

Esquema 22. Estudo enantiosseletivo das reações de nitroaldol utilizando os catalisadores do tipo guanidinas $\mathbf{1 0 6}^{57}$.

A partir desses resultados, os autores fizeram uma proposta para o estado de transição que explicasse a enantiosseletividade obtida na reação de Henry com o organocatalisador 106h. ${ }^{57} \mathrm{O}$ nitroalcano é desprotonado pela guanidina e os grupos $\mathrm{NH}_{2}$ do íon guanidinio formam ligações de hidrogênio com os oxigênios do íon nitronato. O substituinte aromático da guanidina e o substituinte $\mathrm{R}_{2}$ do aldeído se posicionam de forma a diminuir os efeitos estéreos. Dessa forma, o ataque à face Si do aldeído é favorecido devido ao estado de transição formado, mostrando ser a configuração $(S)$ mais estável (Figura 9).

A enantiosseletividade nas reações de Henry pode ser associada pela ativação do composto carbonílico através de ligações de hidrogênio, levando ao bloqueio parcial de uma das faces devido ao ambiente quiral gerado pelo organocatalisador, como proposto por Shi e colaboradores ${ }^{56}$ para organocatalisadores do tipo tiouréias. Ou ainda, a enantiosseletividade pode advir da 
formação de um ambiente favorável para a aproximação do aldeído apenas por uma das faces do íon nitronato ao aldeído. Neste caso, os oxigênios do íon nitronato é que formam as ligações de hidrogênio com o íon guanidínio, bloqueando umas das faces do íon nitronato como proposto por Terada e colaboradores ${ }^{57}$.

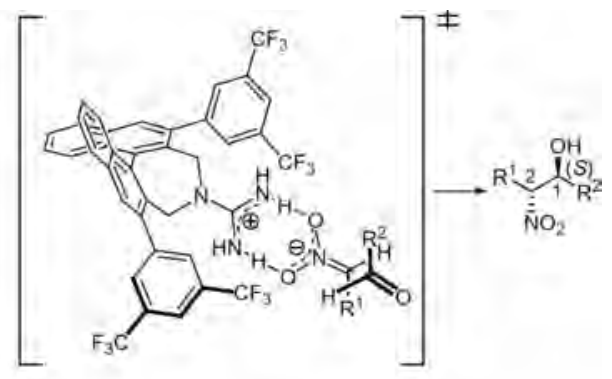

Figura 9. Estado de transição para reação de Henry com um organocatalisador do tipo guanidina ${ }^{57}$.

Os produtos enantiopuros das reações de Henry são importantes intermediários para síntese de diversos produtos naturais e compostos com interesse farmacêutico. Em 2010, Cossy e colaboradores ${ }^{58}$ propuseram a utilização do organocatalisador $\mathbf{1 1 0}$ do tipo cinchonina em uma das etapas da síntese da morfolina 2,2-dissubstituída 112, substância essa utilizada no tratamento de esquizofrenia e depressão. A etapa-chave envolve uma reação de nitroaldol enantiosseletiva entre o precurssor 109 e nitrometano, para formar o intermediário sintético 111. O aduto de Henry 111 foi obtido em 76\% de rendimento e 96\% de excesso enantiomérico (Esquema 23).

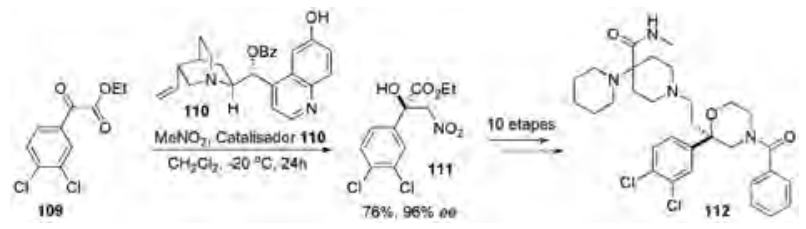

Esquema 23. Aplicação da reação de Henry na síntese do composto biotivo $112^{58}$.

Nagasawa e colaboradores ${ }^{59}$ desenvolveram uma nova classe de organocatalisadores bifuncionais contendo tanto o núcleo guanidínico quanto o grupo tiouréia para aplicação em catálise enantiosseletiva nas reações de Henry. Diferentes organocatalisadores foram sintetizados e aplicados em quantidades catalíticas (10 mol\%) nas reações entre o nitrometano e diferentes aldeídos alifáticos $\alpha$-substituídos. Dentre todos os catalisadores testados, o catalisador $\mathbf{1 1 4}$ foi o que apresentou os melhores rendimentos (70-91\%) e excessos enantioméricos (82-92\%), quando na presença de $50 \mathrm{~mol} \%$ de iodeto de potássio e $5 \mathrm{~mol} \%$ de hidróxido de potássio (Esquema 24).

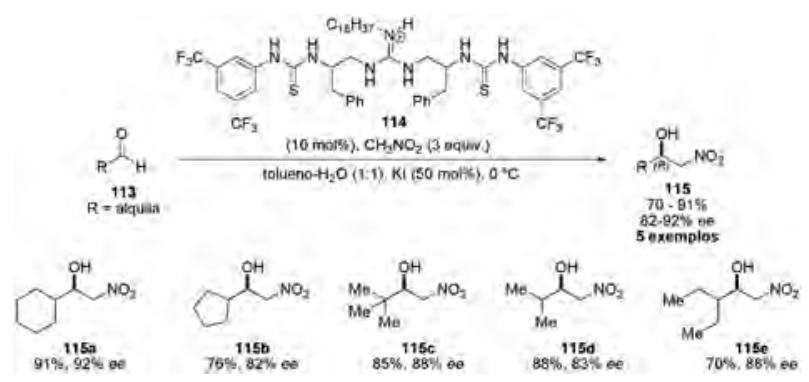

Esquema 24. Aplicação de organocatalisadores bifuncionais do tipo guanidina-tiouréia em reações de Henry enantiosseletivas ${ }^{59}$.

Os autores propuseram estados de transição que justificam a enantiosseletividade $(R)$ dos produtos obtidos. Tanto o íon nitronato gerado in situ quanto o aldeído se coordenam com o catalisador através de interações de hidrogênio pelos sítios guanidínio e tiouréia, respectivamente. A conformação anti é mais favorecida em relação à conformação gauche devido ao menor impedimento estéreo quando o grupo R do aldeído está o mais afastado do íon nitronato (Figura 10).
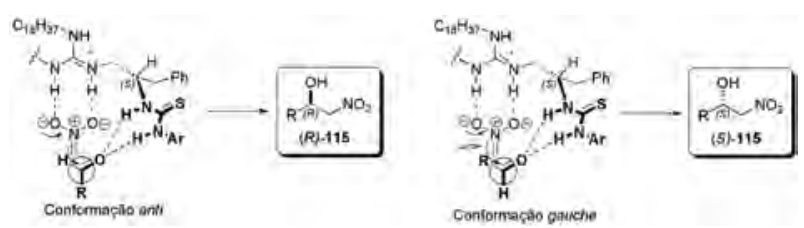

Figura 10. Estruturas dos estados de transição propostos por Nagasawa e colaboradores que justificam a configuração $R$ dos adutos de Henry catalisados pelo catalisador bifuncional $\mathbf{1 1 4}^{59}$.

As modificações estruturais nos alcalóides cinchona são bastante comuns. Hiemstra e colaboradores ${ }^{60}$ realizaram tais modificações inserindo tiouréias no anel quinolínico da cinchona para posterior investigação de sua eficiência nas reações de Henry. A metodologia foi estabelecida variandose solvente e temperatura. Os melhores resultados foram obtidos quando as reações foram realizadas utilizado 10 
mol\% do catalisador 116 e THF como solvente a uma temperatura de $-20{ }^{\circ} \mathrm{C}$. Vários aldeídos aromáticos foram testados e os produtos de nitroaldol foram isolados em 90-99\% de rendimento e excessos enantioméricos que variaram de 85-92\%. Já a utilização de $\mathbf{1 1 7}$ (enantiômero do catalisador 116) forneceu os produtos de nitroaldol (R)-105 em rendimentos similares (87-97\%) e excessos enantioméricos de 87-93\% (Esquema 25).

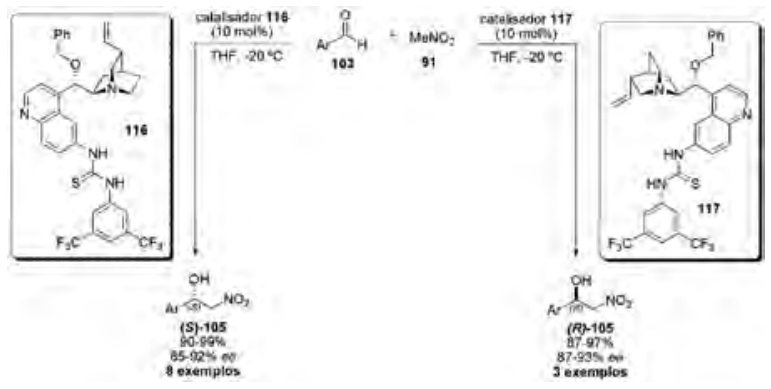

Esquema 25. Reação de Henry enantiosseletiva utilizando os alcalóides cinchona modificados 116 e 117 como organocatalisadores ${ }^{60}$.

Apesar dos autores mencionarem que não está claro o processo pelo qual os catalisadores 116 e 117 induzem a enantiosseletividade, eles propuseram um arranjo do estado de transição no qual o aldeído coordena, através de ligações de hidrogênio, ao sítio da tiouréia e ao íon nitronato gerado in situ pela desprotonação do nitrometano pelo sítio básico do anel quinuclidínico do catalisador (Figura 11). Os autores acreditam que o aumento da enantiosseletividade está relacionado com a alta liberdade conformacional do catalisador 116 uma vez que os resultados por eles obtidos não podem ser relacionados com a polaridade do solvente.

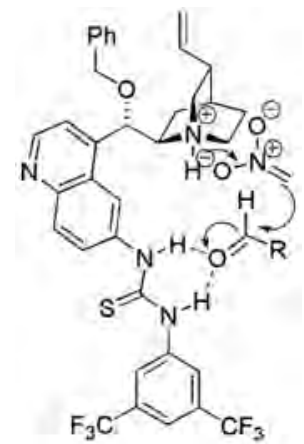

Figura 11. Estado de transição proposto por Hiemstra e colaboradores para justificar a enantiosseletividade dos adutos de Henry catalisados pela chinchona tiouréia modificada $\mathbf{1 1 6}^{60}$.

\section{Conclusão}

A organocatálise é um dos campos da química orgânica de maior destaque e de grande potencial da atualidade, o que tem despertado o interesse de muitos grupos de pesquisa no mundo todo. Esse interesse se deve à praticidade das metodologias e às altas seletividades obtidas nas diferentes reações já estudadas, tais como, reações de adição aldólica, adição de Michael e reações de Henry.

Mais recentemente, esforços têm sido aplicados na síntese de novos organocatalisadores quirais, seja por pequenas modificações estruturais de moléculas já empregadas em organocatálise como os aminoácidos, alcalóides naturais do tipo cinchonas e cinchonidinas, até mesmo a síntese de guanidinas, tiouréias e sulfonamidas quirais, o que tem se mostrado como um ramo em pleno crescimento para aplicação e desenvolvimento de metodologias em sínteses enantiosseletivas.

Aliado à síntese desses novos organocatalisadores, o estudo mecanístico e de estados de transição para as reações de aldol, Michael e Henry tem se tornado cada vez mais claro, permitindo a síntese de novos catalisadores a partir da compreensão do modo de ação daqueles já existentes. $\mathrm{O}$ fato dos produtos obtidos nessas reações serem úteis como intermediários para síntese de moléculas de interesse biológico faz da catálise assimétrica aplicada a estas reações um campo promissor e em constante desenvolvimento.

\section{Referências Bibliográficas}

1. Barreiro, E. J.; Ferreira, FR. R.; Quím. Nova, 1997, 20, 647.,

2. List, B.; Tetrahedron 2002, 58, 5573.

3. List, B.; Chem. Rev. 2007, 107, 5413.

4. Amarante, G. W.; Coelho, F.; Quím. Nova 2009, 32, 469.

5. a) List, B.; Lerner, R. A.; Barbas III, C. F.; J. Am. Chem. Soc. 2000, 122, 2395. b) Northrup, A. B.; MacMillan, D. W. C.; J. Am. Chem. Soc. 2002, 124, 6798. c) Northrup, A. B.; MacMillan, D. W. C.; Science 2004, 305, 1752. d) Hazelard, D.; Ishikawa, H.; Hashizume, D.; Koshino, H.; Hayashi, Y.; Org. Lett. 2008, 10, 1445.

6. a) List, B.; Pojarliev, P.; Biller, W. T.; Martin, H. J.; J. Am. Chem. Soc. 2002, 124, 827. b) Kantam, M. L.; Rajasekhar, C. V.; Gopikrishna, G.; Reddy, K. R.; Choudary, B. M.; Tetrahedron Lett. 2006, 47, 5965. c) Ting, A.; Schaus, S. E.; Eur. J. Org. Chem. 2007, 5797. d) Yang, J. W.; Chandler, C.; Stadler, M.; Kampen, D.; List, B.; Nature 2008, 452, 453. e) List, B.; J. Am. Chem. Soc. 2000, 122, 9336. 
7. a) List, B.; Pojarliev, P.; Martin, H. J.; Org. Lett. 2001, 3, 2423. b) Hong, B.-C.; Nimje, R. Y.; Wu, M.-F.; Sadani, A. A.; Eur. J. Org. Chem. 2008, 1449 .

8. Tungler, A.; Fogassy, G.; J. Mol. Cat. A: Chem. 2001, 173, 231.

9. Shi, M.; Jiang, J. K.; Li, C. Q.; Tetrahedron Lett. 2001, 43, 127.

10. a) Faller, J. W.; Lavoie, A. R.; Grinmmond, B. J.; Organomet. 2002, 21, 1662. b) Aasato, A. E.; Watanabe, C.; Li, X. Y.; Liu, R. S. H.; Tetrahedron Lett. 1992, 33, 3105. c) Ahrendt, K. A.; Borths, C. J.; MacMillan, D. W. C.; J. Am. Chem. Soc. 2000, 122, 4243.

11. a) Guillena, G.; Ramón, D. J.; Yus, M.; Tetrahedron: Asymmetry 2007, 18, 693. b) Enders, D.; Hüttl, M. R. M.; Grondal, C.; Raabe, G.; Nature 2006, 441, 861.

12. Beeson, T. D.; Mastracchio, A.; Hong, J-B.; Ashton, K.; MacMillan, D. W. C.; Science 2007, 316, 582.

13. Movassaghi, M.; Jacobsen, E. N.; Science 2002, 298, 1904.

14. Prefácio: Kocovsky, P.; Malkov, A. V.; Tetrahedron 2006, 62, 255.

15. a) List, B.; Hoang, L.; Martin, H. J.; PNAS 2004, 101, 5839. b) Bahmanyar, S.; Houk, K. N.; J. Am. Chem. Soc. 2001, 123, 12911. c) Bahmanyar, S.; Houk, K. N.; Org. Lett. 2003, 5, 1249. d) Allemann, C.; Gordillo, R.; Clemente, F. R.; Cheong, P. H.-Y.; Houk, K. N.; Acc. Chem. Res. 2004, 37, 558. e) Clemente, F. R.; Houk, K. N.; J. Am. Chem. Soc. 2005, 127, 11294. f) Hoang, L.; Bahmanyar, S.; Houk, K. N.; List, B.; J. Am. Chem. Soc. 2003, $125,16$.

16. a) Dalko, P. I.; Moisan, L.; Angew. Chem. Int. Ed. 2001, 40, 3726. b) Gaunt, M. J.; Johansson, C. C. C.; McNally, A.; Vo, N. T.; Drug Discovery Today 2007, 12, 8.

17. MacMillan, D. W. C.; Nature 2008, 455, 304.

18. Heathcock, C. H.; “Asymmetric Synthesis” Vol. 3 - Parte B, p. 116, New York, Academic Press, Inc, 1984.

19. Paterson, I.; Pure Appl. Chem. 1992, 64, 1821.

20. a) Hajos, Z. G.; Parrish, D. R.; Asymmetric Synthesis of Optically Active Polycyclic Organic Compounds. German Patent DE 2102623, July 29, 1971. b) Hajos, Z. G.; Parrish, D. R.; J. Org. Chem. 1974, 39, 1615.

21. a) Eder, U.; Sauer, G.; Wiechert, R.; Optically active 1,5-Indanone and 1,6-Napthalenedione. German Patent DE 2014757, Oct. 7, 1971. b) Eder, U.; Sauer, G.; Wiechert, R.; Angew. Chem. Int. Ed. Engl. 1971, 10, 496.

22. List, B.; Lerner, R. A.; Barbas III, C. F.; J. Am. Chem. Soc. 2000, 122, 2395.

23. Guillena, G.; Nájera, C.; Ramón, D. J.; Tetrahedron: Asymmetry 2007, 18, 2249.

24. a) List, B.; Pojarliev, P.; Castello, C.; Org. Lett. 2001, 3, 573. b) Sakthivel, K.; Notz, W.; Bui, T.; Barbas III, C. F.; J. Am. Chem. Soc. 2001, 123, 5260.

25. a) Saito, S.; Yamamoto, H.; Acc. Chem. Res. 2004, 37, 570. b) Tang. Z.; Jiang, F.; Yu, L. T.; Cui, X.; Gong, L. Z.; Mi, A. Q.;
Jiang, Y. Z.; Wu, Y. D.; J. Am. Chem. Soc. 2003, 125, 5262. c) Nakadai, M.; Saito, S.; Yamamoto, H.; Tetrahedron 2002, 58, 8167. d) Hayashi, Y.; Sekizawa, H.; Yamaguchi, J.; Gotoh, H.; J. Org. Chem. 2007, 72, 6493.

26. Pan, Q.; Zou, B.; Wang, Y.; Ma, D.; Org. Lett. 2004, 6, 1009.

27. a) Chandrasekhar, S.; Narsihmulu, C.; Reddy, N. R.; Sultana, S. S.; Tetrahedron Lett. 2004, 45, 4581. b) MacMillan, D. W. C.; Northrup, A. B.; J. Am. Chem. Soc. 2002, 124, 6798.

28. a) Bahmanyar, S.; Houk, K. N.; J. Am. Chem. Soc. 2001, 123, 12911. b) Bahmanyar, S.; Houk, K. N.; J. Am. Chem. Soc. 2001, 123, 11273. c) Bahmanyar, S.; Houk, K. N.; Martin, H. J.; List, B.; J. Am. Chem. Soc. 2003, 125, 2475. d) Clemente, F. R.; Houk, K. N.; Angew. Chem. Int. Ed. 2004, 43, 5766. e) Calderón, F.; Doyagüez, E. G.; Cheong, P. H-Y.; Fernández-Mayoralas, A.; Houk, K. N.; J. Org. Chem. 2008, 73, 7916.

29. a) List, B.; Yang, J. W.; Science 2006, 313, 1584. b) Seayad, J.; List, B.; Org. Biomol. Chem. 2005, 3, 719.

30. Peng, F.; Shao, Z.; J. Mol. Cat. A.: Chem. 2008, 285, 1.

31. Berkessel, A.; Gröger, H.; “Asymmetric Organocatalysis - From Biomimetic Concepts to Applications in Asymmetric Synthesis", $2^{\mathrm{a}}$ edição, p. 45, Weinheim, Wiley-VCH, 2006.

32. Song, C. E.; “Cinchona Alkaloids in Synthesis \& Catalysis”, $1^{\mathrm{a}}$ edição, p. 24, Weinheim, Wiley-VCH, 2009.

33. Zhang, F.-Y.; Corey, E. J.; Org. Lett. 2000, 2, 1097.

34. Perrard, T.; Plaquevent, J.-C.; Desmurs, J.-R.; Hébrault, D.; Org. Lett. 2000, 2, 2959.

35. Halland, N.; Aburel, P. S.; Jorgensen, K. A.; Angew. Chem. Int. Ed. 2003, 43, 661.

36. Yamaguchi, M.; Shiraishi, T.; Hirama, M.; J. Org. Chem. 1996, $61,3520$.

37. List, B.; Pojarliev, P.; Martin, H. J; Org. Lett. 2001, 3, 2423.

38. List, B.; J. Am. Chem. Soc. 2000, 122, 9336.

39. (a) List, B.; Lerner, R. A.; Barbas III, C. F.; J. Am. Chem. Soc. 2000, 122, 2395. (b) Notz, W.; List, B.; J. Am. Chem. Soc. 2000, 122, 7386. (c) List, B.; Pojarliev, P.; Castello, C.; Org. Lett. 2001, 3, 573.

40. Enders, D.; Seki, A.; Synlett 2002, 26.

41. Lu, A.; Liu, T.; Wu, R.; Wang, Y.; Wu, G.; Zhou, Z.; Fang, J.; Tang, C.; J. Org. Chem. 2011, 76, 3872.

42. Wei, S.; Yalalov, D. A.; Tsogoeva, S. B.; Schmatz, S.; Catal. Today 2007, 121, 151.

43. (a) Li, X.-F.; Cun, L.-F.; Lian, C.-X.; Zhong, L.; Chen, Y.-C.; Liao, J.; Zhu, J.; Deng, J.-G.; Org. Biomol. Chem. 2008, 6, 349. (b) Russo, A.; Perfetto, A.; Lattanzi, A.; Adv. Synth. Catal. 2009, 351, 3067. (c) Ren, Q.; Gao, Y.-J.; Wang, J.; Chem. Eur. J. 2010, 16, 13594.

44. Hu, Z.-P.; Lou, C.-L.; Wang, J.-J.; Chen, C.-X., Yan, M.; J. Org. Chem. 2011, 76, 3797. 
45. Li, X.-M.; Wang, B.; Zhang, J.-M.; Yan, M.; Org. Lett. 2011, 13, 374.

46. McCooey, S. H.; Connon, S. J.; Org. Lett. 2007, 9, 599.

47. Allu, S.; Selvakumar, S.; Singh, V. K.; Tetrahedron Lett. 2010, 51, 446.

48. Lin, A.; Wang, J.; Mao, H.; Ge, H.; Tan, R.; Zhu, C.; Cheng, Y.; Org. Lett. 2011, 13, 4176.

49. Gotoh, H.; Ishikawa, H.; Hayashi, Y.; Org. Lett. 2007, 9, 5307.

50. Hanessian, S.; Stoffman, E.; Mi, X.; Renton, P.; Org. Lett. 2011, 13, 840 .

51. Yang, H.; Carter, R. G.; J. Org. Chem. 2010, 75, 4929.

52. Henry, L; Seances, C. R. H.; Acad. Sci. 1895, 120, 1265.

53. Palomo, C.; Oiarbide, M.; Laso, A.; Eur. J. Org. Chem. 2007, 21, 2561.

54. Boruwa, J.; Gogoi, N.; Saikia, P. P.; Barua, N. C.; Tetrahedron: Asymmetry 2006, 17, 3315.

55. Luzzio, F. A.; Tetrahedron 2001, 57, 915.

56. Liu, X.; Jiang, J.; Shi, M.; Tetrahedron: Asymmetry 2007, 18, 2773.
57. Ube, H.; Terada, M.; Bioorg. Med. Chem. Lett. 2009, 19, 3895.

58. Cochi, A.; Métro, T.-X.; Pardo, D. G.; Cossy, J.; Org. Lett. 2010, 12, 3693.

59. Sohtome, Y.; Hashimoto, Y.; Nagasawa, K.; Adv. Synth. Catal. 2005, 347, 1643.

60. Marcelli, T.; van der Haas, R. N. S.; van Maarseveen, J. H.; Hiemstra, H.; Angew. Chem. Int. Ed. 2006, 45, 929.

\section{Diego S. Alves, Milenna M. Sena, Felipe A. Viana \& Rafael O. Rocha*}

Laboratório de Isolamento e Transformação de Moléculas Orgânicas (LITMO), Instituto de Química, Universidade de Brasília, Campus Universitário Darcy Ribeiro, C. P. 4478, CEP 70.904-970, Brasília-DF, Brasil

*e-mail: rafaelrocha@unb.br 